\title{
LA INDUSTRIA HARINERA EN LA PROVINCIA DE LEÓN DURANTE EL FRANQUISMO: LA FÁBRICA DE HARINAS «MARINA LUZ» DE GORDONCILLO
}

\author{
Javier REVILLA CASADO \\ Universidad de León
}

\begin{abstract}
RESUMEN: El cultivo del cereal y su transformación industrial en harina constituyen aspectos básicos para la alimentación humana, máxime en condiciones difíciles. En el contexto de la Guerra Civil española surge una pequeña factoría (1936) en la localidad de Gordoncillo y se desarrolla durante la dura posguerra caracterizada por la autarquía económica. En los años sesenta sufre la fuerte crisis del sector harinero español, ante la que sucumbe. El estudio de la fábrica de harinas «Marina Luz», situada en la comarca de Tierra de Campos, provincia de León, nos sirve para comprender la evolución del sector harinero durante la dictadura franquista.
\end{abstract}

PALABRAS CLAVE: Fábrica de harinas, Autarquía, Franquismo, Guerra Civil española, Cultivo cerealista, Villa de Gordoncillo, Comarca Tierra de Campos, Provincia de León (España).

ABSTRACT: The growing of cereals and its industrial transformation into flour are basic points for the human diet, even more in hard conditions. In the context of the Spanish Civil war, a little factory emerges (1936) in Gordoncillo (province of León) and it develops throughout the hard post-war, which is characterized by the economical autarchy. In the 1960s, the Spanish flour sector suffers an important crisis and the little factory in Gordoncillo succumbs. The history from the so called "Marina Luz" flour mill, which lays on the so called "Land of fields" area, helps us to understand the evolution of the flour sector during the Franco's regime.

KEYWORDS: Flour mill, Autarchy, Franco's regime, Spanish Civil war, Growing of cereal, Village of Gordoncillo, Region of Tierra de Campos (Land of fields), Province of León (Spain).

\section{EL SECTOR HARINERO EN LA PROVINCIA DE LEÓN}

Fábrica de harinas se asocia generalmente al amplio edificio destinado a la molturación de cereales panificables en grandes cantidades. Más aún, se relaciona dicha denominación con las instalaciones que incorporan el sistema austro-húngaro o de reducción progresiva. Sin embargo, también existieron fábricas que molturaban por medio de muelas o ruedas de piedra, e incluso mixtas. Por ello hay que precisar que la diferencia entre molino y fábrica no radica en el tamaño del 
edificio ni en la tecnología que incorpora, sino en el sistema económico que lleva aparejado.

Así, en el molino un porcentaje del cereal que se lleva a molturar es tomado por el molinero en concepto de pago por desarrollar su actividad, en lo que se conoce como maquila ${ }^{1}$. Con la implantación del capitalismo la molinería se transformó, apareciendo la molturación en régimen de fábrica donde un empresario se encarga de la compra del cereal, de su transformación y de la venta de la harina y del resto de productos. Por ello, los molineros diferencian entre baja molinería o maquilera cuando se realiza en molinos y alta molienda cuando se efectúa en fábricas.

Dentro de la industria agroalimentaria española, la harinera ha constituido un importante sector, incluso el mayor en algunas épocas. En 1856, cuando todavía no se había patentado el sistema austro-húngaro que revolucionará técnicamente la industria, en España se contabilizaban un total de 87 fábricas de harinas². Progresivamente se irán sustituyendo los molinos maquileros por industrias y el número de harineras se incrementará década a década, favorecido primero por los monopolios comerciales en las colonias y posteriormente por la demanda europea en el contexto de la Gran Guerra. De hecho, no sólo se disparó el número de establecimientos, sino también la capacidad de molturación del país, muy por encima de las necesidades reales, factor que produjo posteriormente una gran incertidumbre en el sector y que llevó a que durante la dictadura de Primo de Rivera se decretase la prohibición de ampliar las fábricas de harinas o de abrir nuevas instalaciones ${ }^{3}$. Pese a todo se siguió especulando, especialmente tras la Guerra Civil, ya que el modelo económico autárquico implantado por el primer franquismo permitió una nueva oleada de instalaciones harineras.

En la provincia leonesa, la abundancia de cursos fluviales favoreció la instalación de molinos hidráulicos. Así, el artefacto más antiguamente documentado nos lleva al año $875^{4}$. A lo largo de las edades Media, Moderna y

${ }^{1}$ Según el diccionario de la RAE, maquila procede del árabe hispánico makíla, y este del árabe clásico makīlah, que significa "cosa medida” y se define como porción de grano, harina o aceite que corresponde al molinero por la molienda.

2 Estadística Administrativa de la Contribución Industrial, 1856. Citado por Moreno LÁzARo (1990). La industria harinera... p. 40, cuadro II.

${ }^{3}$ Decreto-Ley del 9 de julio de 1926.

${ }^{4}$ SÁEZ (1987). Colección documental... pp. 50-52, doc. 34: 30 de enero de 915, pleito sostenido por Velasco, representante del monasterio de Santiago de Valdevimbre, con Munio y sus hermanos, sobre el agua del Bernesga que alimenta los molinos del monasterio, en el que se evidencia que Vimara y sus hijos Lup y Godesteo habían tomado agua de dicho río tres años antes de la batalla de Polvoraria, haciendo presa y molino que luego cedieron al monasterio. 
Contemporánea serán miles los molinos que se constaten en León, convirtiéndose en elementos destacables dentro de las economías locales. En 1862 la Guía fabril e industrial de España indica que en la provincia existían un total de 1.695 molinos con 2.005 piedras $^{5}$.

Parece ser que la primera fábrica de harinas leonesa se instaló entre 1845 y 1849, sobre un antiguo molino en el término de Armunia. La harinera tuvo tres piedras y su iniciativa se debió al empresario catalán Antonio Jover y al comerciante asturiano José Domingo Salgado, que ampliaron su inversión en $1860^{6}$. En 1867 García de La Foz dice que "existe una fábrica de harinas, única en su clase en el país, a una media legua de León cerca del pueblo de Trobajo de Arriba, propia de D. Gregorio Salcedo, perfectamente montada y movida por las aguas de una acequia sangrada del Bernesga"7 . Si Trobajo de Arriba se corresponde con el actual Trobajo del Camino nos inclinamos a pensar que es la misma fábrica que anteriormente se nos citaba ubicada en Armunia, dada su cercanía. De hecho, todo hace indicar que ambas fuentes se están refiriendo al lugar que actualmente ocupa la fábrica de harinas "Santiago Alfageme y Cía.”, en la localidad de Oteruelo de la Valdoncina.

Podemos documentar otras harineras leonesas en el siglo XIX. En 1860 se pone a la venta «La Dolores», emplazada en Mansilla Mayor ${ }^{8}$ y en 1868 la viuda de Antonio Santos arrienda "la acreditada fábrica de harinas, sita en la Era del moro" de la ciudad de León? .

El libro Economía leonesa, pequeña historia de su evolución (1907-1957) menciona la instalación de dos nuevas fábricas en 1909, "J. Crespo y Hermanos" situada en Palanquinos y "Santiago Alfageme e Hijos" nuevamente ubicada en Armunia. Poco después surgirían en Astorga las de "Alonso Botas y Sobrino" (1911) y la de "Panero Crespo y Botas" (1912) ${ }^{10}$. En 1920 en la provincia de León existían activas 13 fábricas de harinas: León, Santovenia, Armunia, Sahagún, Santas Martas, Palanquinos, Valderas, Bercianos del Páramo, Cistierna, La Pola de Gordón, Riaño y las dos de Ponferrada ${ }^{11}$. En 1958 la provincia leonesa tenía 30

\footnotetext{
${ }^{5}$ JIMÉNEZ Y GUITED (1862).

${ }^{6}$ Moreno Lázaro (1998).

${ }^{7}$ García De LA Foz (1867). Crónica..., pp. 11-12.

${ }^{8}$ BOPL. Número 119 de 1860.

${ }^{9}$ BOPL. Números 87 y 88 de 1868 y 24 de 1869.

${ }^{10}$ CÁmARA Oficial... (1957). Economía Leonesa... sin p.

${ }^{11}$ ACOCIL. Libro de Censo Industrial. 1920/21.
} 
fábricas de harinas ${ }^{12}$, una de ellas la de Gordoncillo cuyo estudio ${ }^{13}$ nos va a servir para conocer el proceso de desarrollo, auge y decadencia de esta industria en las décadas centrales del pasado siglo XX.

El término municipal de Gordoncillo se sitúa en la Tierra de Campos leonesa, comarca eminentemente cerealista. Hace límite al oeste con la provincia de Valladolid, línea en parte marcada por el río Cea. Su base económica siempre ha estado apoyada en el sector primario, cultivándose en su terruño la vid y los cereales. Su importancia ganadera tuvo relación con el paso por el municipio del Cordel de la Zamorana.

Desde el siglo XIV Gordoncillo gozaba de magníficas comunicaciones gracias al Camino Real entre la cornisa cantábrica y la meseta castellana, importante ruta comercial que en el siglo XVIII se había ampliado y unía Santander, Avilés, León, Toro y Madrid. Para esta vía en 1745 se inició la construcción de un puente de piedra sobre el río Cea, a dos kilómetros de Gordoncillo. Sin embargo, el paso de los siglos ha ido relegando a la zona a una situación secundaria en cuanto a las comunicaciones.

En el siglo XVIII el Gobierno no estimó el anteproyecto del ingeniero francés Carlos Lemaur, que propuso sendos ramales del Canal de Castilla que comunicasen Castil de Vela (Palencia) con León y Zamora, el primero pasando por Valencia de Don Juan y el segundo por Benavente ${ }^{14}$. De haber prosperado la idea de Lemaur puede que alguno hubiera discurrido por Gordoncillo, por lo que el desarrollo económico de la villa habría sido notable. Con toda seguridad se habrían instalado fábricas de harinas aprovechando los saltos de agua de dichos canales.

A comienzos del siglo XX también se perdió otra oportunidad, pues la línea ferroviaria de vía estrecha entre Medina de Rioseco y Palanquinos, inaugurada el 14 de abril de 1915, finalmente no transcurrió por Gordoncillo, como parece ser que establecía el proyecto inicial del tramo entre Valderas y Valencia de Don Juan al que se impusieron los intereses políticos del ministro y diputado Demetrio Alonso Castrillo. Lo cierto es que el paso del ferrocarril hubiese supuesto un claro

12 Ibídem. 1958.

13 Este artículo está basado en la memoria histórica que se nos encargó para el proyecto de rehabilitación y puesta en valor del complejo industrial, que plasmamos en el trabajo: La fábrica de harinas «Marina Luz» de Gordoncillo (León). Historia de una pequeña industria terracampina, Depósito Legal LE-7-2008.

${ }^{14}$ Helguera, García Tapia y Molinero (1988). El Canal de Castilla, p. 28. 
progreso para Gordoncillo ya que habría adelantado y potenciado su desarrollo industrial.

\section{LA FÁBRICA DE HARINAS «MARINA LUZ» DE GORDONCILLO}

\subsection{Antecedentes}

Por el emplazamiento de la localidad ya hemos indicado su destacada producción cerealista. En relación con ello, la documentación del Archivo Municipal de Gordoncillo (en adelante, AMG) recoge abundantes datos alusivos al Pósito municipal o Panera del Pósito ${ }^{15}$. En ella se nos indican las cuentas anuales, los nombres de los depositarios, las reparaciones del edificio o los repartos del grano en él almacenado ${ }^{16}$. En la sesión del 24 de febrero de 1906 se hace destacar su estado ruinoso ${ }^{17}$ y el 17 de noviembre del mismo año la Corporación acuerda proceder a su retejado ${ }^{18}$. Finalmente en la sesión del 2 de octubre de 1909 se acuerda vender la casa-panera del pósito ${ }^{19}$, que se subasta el 13 de mayo de 1911, aunque queda en posesión del propio Ayuntamiento que decide aprovechar dos de sus muros de tapia real para crear un juego de pelota ${ }^{20}$, cuyas obras estaban concluidas un año después ${ }^{21}$. Este frontón se situaba en plena Plaza Mayor de la villa y fue derribado en la década de 1960 . De entre sus escombros se rescató la inscripción fundacional sobre piedra ${ }^{22}$ que dice:

R[EA]L POSITO DE LA V[ILLA]
DE GORDONZILLO
CONSTRVIDO A ES
PEИS[A]S DE SVS CAVD[ALE]S
REIИ[AN]DO CARLOS IV
АЙО DE 1799

La importancia vitivinícola de Gordoncillo se vio gravemente afectada por la filoxera, enfermedad cuya aparición se constata por primera vez en la localidad el

\footnotetext{
${ }^{15}$ Para conocer el funcionamiento de estas instituciones recomendamos: CARASA SOTO (1983).

${ }^{16}$ Los repartos del grano se realizan siempre en los meses de diciembre y enero. Se especifica cuando se entrega centeno a los labradores pobres.

${ }^{17}$ AMG. Libros de sesiones, tomo 6 $6^{\circ}$, folios 40 y 41. Sesión ordinaria del 24 de febrero de 1906.

${ }^{18} \mathrm{Ibídem}$, tomo $7^{\circ}$, folio 5 (recto). Sesión ordinaria del 17 de noviembre de 1906.

${ }^{19}$ Ibídem, tomo 8 ${ }^{\circ}$, folios 16 y 17. Sesión ordinaria del 2 de octubre de 1909.

${ }^{20}$ Ibídem, tomo 9 $9^{\circ}$, folio 8 (recto). Sesión ordinaria del 13 de mayo de 1911.

${ }^{21}$ Ibídem, tomo 9º folio 30 (recto). Sesión ordinaria del día 04 de mayo de 1912.

${ }^{22}$ Esta inscripción está hoy guardada en dependencias municipales.
} 
13 de enero de $1906^{23}$. Este factor favoreció aún más la ampliación de los suelos cultivados con cereal. El trigo, principal cereal panificable, era transformado en dos molinos movidos por las aguas sangradas del río Cea, llamados de la Berraca y de la Granja de Béjar. Ninguno de los dos consta documentado como de Gordoncillo, pues se sitúan fuera de su término municipal, pero ambos fueron explotados por esta localidad.

El molino de Mantilla o de la Berraca se sitúa a dos kilómetros del casco urbano de Gordoncillo, cerca de un importante vado del Cea donde se emplaza el histórico puente al que ya nos hemos referido. El artefacto, cuyos restos arruinados han llegado hasta la actualidad, se configura mediante cárcavos de piedra y muros alzados en adobe, dentro de los cuales se encontraban varias parejas de piedras en la planta baja, y aparatos de cernido en la planta superior. Según testimonios orales dejó de molturar hacia 1960.

El molino de la Granja de Béjar se encuentra en la finca que le da nombre. Está mucho mejor conservado, aunque sin actividad fabril desde hace bastantes décadas. Su edificio es de ladrillo y guarda toda la maquinaria, incluidas las dos parejas de ruedas con las que molturaba el grano.

Además de ellos, a comienzos del siglo XX se construyó un nuevo molino, esta vez emplazado dentro del casco urbano de Gordoncillo y que será el precedente directo de la fábrica de harinas «Marina Luz». Se conoció como "el molino del baratillero de Valderas”, apelativo que recibía el industrial Ángel Izquierdo. Son testimonios orales los únicos que hasta el momento hemos podido recabar sobre este artefacto, pues de momento no tenemos referencias documentales escritas. Los informantes consultados nos indican además que la energía necesaria para el movimiento de este artefacto era generada mediante dinamos. En algún momento este establecimiento fue comprado por Germán García Luengos, el empresario que desarrollará la fábrica de harinas adosada precisamente al molino, motivo por el cual desaparecerá consumido por el incendio que en 1944 destruyó también la harinera ${ }^{24}$, como indicaremos más adelante.

Antes de construirse la primera fábrica de harinas, en el solar donde se instalará la gran panera que compartan el SNT y la harinera se propondrá un importante proyecto durante la II República, la construcción de unas nuevas escuelas públicas para la localidad.

${ }^{23}$ AMG. Libros de sesiones, tomo $7^{\circ}$, folio $9 \mathrm{v}$.

${ }^{24}$ Informaciones facilitadas por Raimundo Tejedor Velado (q.e.p.d), molinero de Gordoncillo, entrevistado en León el 8 de noviembre de 2004. 
Gordoncillo tenía importantes necesidades sociales en las primeras décadas del siglo XX. La carencia de un adecuado centro educativo, así como de viviendas para los maestros, se refleja periódicamente en la documentación del AMG. Coincidiendo con las reformas establecidas por el primer gobierno de la Segunda República $^{25}$, el 2 de abril de 1933 el pleno ordinario del Ayuntamiento solicitó al Ministerio de Instrucción Pública la construcción de unas escuelas. El espacio público que el Ayuntamiento designó para ubicar el nuevo centro educativo fueron "los terrenos del común comprendidos entre la carretera de Mayorga, la fábrica de harinas y la ermita” ${ }^{26}$. Esta es la primera cita documental que tenemos sobre la harinera, aunque como veremos posteriormente creemos que todavía no estaba activa.

La solicitud de la construcción de las escuelas se reiteró en la sesión de 31 de marzo de $1934^{27}$. En el archivo municipal hemos encontrado, cosido al Presupuesto Municipal Ordinario para 1934, un sencillo plano a escala 1:200 con la siguiente leyenda "Gordoncillo (León). Croquis de los solares que el Ayuntamiento ofrece para construir en ellos dos escuelas". El esbozo es obra de "B. Cabello. Maestro Nacional." que fue presidente de la Comisión Gestora que se hizo cargo del Ayuntamiento del 26 de enero al 10 de mayo de 1933. Bautista Cabello de la Torre, maestro y alcalde republicano de Gordoncillo, fue por tanto el principal impulsor de este proyecto educativo. Las escuelas solicitadas tendrían 20 metros de ancho por 30 metros de largo, y ocuparían el solar en el que actualmente está la panera que compartieron el SNT y la fábrica de harinas «Marina Luz». Por tanto, en 1933 el terreno ofrecido debía estar vacío y pertenecía al común. Los límites vienen marcados por la calle Real (noroeste) y por la carretera de Mayorga a Valderas (sureste); al noreste se emplaza la ermita del Cristo de la Veracruz y al suroeste el croquis indica la existencia de "huertas", no apareciendo la harinera sí descrita en las actas.

La gestión municipal para la construcción de los edificios escolares continuó en los años siguientes. El 21 de junio de 1936 se celebró una sesión plenaria en la que se dio a conocer una subvención del Gobierno -20.000 pesetas- para la

${ }^{25}$ El ambicioso proyecto educativo puesto en marcha durante el bienio social-azañista (diciembre de 1931 a junio de 1933) logró la construcción de 13.570 escuelas de educación primaria en ese corto periodo de tiempo, cuando entre 1909 y 1931 solamente se habían construido 11.128: MARCOS DEL Olmo (2002). La Segunda República..., p. 32.

${ }^{26}$ AMG. Libros de sesiones, tomo 19º p. 14 y 15. Sesión ordinaria del 2 de abril de 1933.

${ }^{27}$ Ibídem, tomo 19º pp. 72-73. Sesión ordinaria del 31 de marzo de 1934. 
construcción del nuevo centro escolar ${ }^{28}$. En el Centro Documental de la Memoria Histórica se encuentran dos fichas de recomendación referidas a la aprobación del expediente de construcción de las escuelas públicas de Gordoncillo. La primera data del 18 de junio de 1936 y el recomendante es el diputado socialista Rodolfo Llopis $^{29}$, mientras que la segunda data del 20 de junio de 1936 y el recomendante es en este caso el Ministro de Comunicaciones, Bernardo Giner de los Ríos ${ }^{30}$, de Unión Republicana.

En el pleno del 21 de junio de 1936 el Ayuntamiento sacó a subasta pública la construcción de las escuelas. Se menciona el nombre del arquitecto, Luis Aparicio Guisasola $^{31}$. Sin embargo este centro educativo nunca se hará realidad, ya que menos de un mes después se producirá el golpe de estado que desencadenará la Guerra Civil. Con el establecimiento de la dictadura del general Franco, el proyecto de las escuelas quedará varios años en el olvido. A mediados de 1941 el arquitecto que había realizado los planos reclamó el pago de los mismos y el Ayuntamiento acordó hacérselo efectivo ${ }^{32}$. En 1946 el Ministerio de Educación comunicó que el expediente de construcción de las escuelas de Gordoncillo se había extraviado ${ }^{33}$. Finalmente en 1949 se solicitó la construcción de un nuevo centro educativo pero ya no en el emplazamiento acordado en el proyecto republicano, sino en el barrio de San Roque ${ }^{34}$.

\subsection{La panera del Servicio Nacional del Trigo}

El gran almacén de cereales al que nos referimos fue construido o arrendado por el Servicio Nacional del Trigo ${ }^{35}$ (SNT). Durante la Guerra Civil, en el territorio ocupado por los sublevados, José Larraz propuso crear una Corporación Nacional del Trigo, idea completada por el vallisoletano Dionisio Martín Sanz en su artículo "El problema triguero y el Nacional-Sindicalismo" y que finalmente convergieron

${ }^{28}$ Ibídem, tomo $20^{\circ}$. Sesión ordinaria del 21 de junio de 1936.

${ }^{29}$ CDMH. PS-MADRID, 636,1, 166.

${ }^{30}$ Ibídem, 167.

31 AMG. Libros de sesiones, tomo 20․ Sesión ordinaria del día 21 de junio de 1936. Luis Aparicio Guisasola fue arquitecto municipal de Astorga y posee abundantes edificaciones en la provincia de León.

${ }^{32}$ Ibídem, 1941.

33 Ibídem, 1946.

${ }^{34}$ Ibídem, 1949. El solar no se comprará hasta 1961.

35 Sobre el origen y funcionamiento del SNT hemos consultado la tesis doctoral de BARCIELA LÓPEZ (1981). 
en el Decreto-Ley de Ordenación Triguera de 23 de agosto de 1937, publicado dos días después en el BOE, que creó definitivamente el $\mathrm{SNT}^{36}$.

La investigación de Carlos Barciela echa por tierra los éxitos que el propio régimen franquista se atribuyó con la intervención estatal en el sector cerealista ${ }^{37} \mathrm{y}$ concluye que la actuación del SNT fue negativa y contraproducente para los campesinos por "los bajos precios de tasa y los cupos de entrega obligatoria a precios muy inferiores a los que se pagaba el cupo de excedente y, por supuesto, a los vigentes en el mercado negro" 38 . Según el mismo autor, las características de la autarquía de los años cuarenta fueron: escasez, carestía, pérdida de calidad, necesidad de recurrir a importaciones masivas, comercio clandestino y corrupción. Estos problemas se atemperaron desde 1951, año en que fue nombrado Ministro de Agricultura el liberal Rafael Cavestany. Gracias a ello aumentó la producción y se impulsó, por fin, la Red Nacional de Silos y Graneros ya aprobada por el gobierno republicano del Frente Popular. Sin embargo, la liberalización económica de los años sesenta no afectó al comercio del trigo, que siguió monopolizado por el SNT, ni se paliaron las consecuencias de la caída de la demanda interna, lo que provocó grandes excedentes de cereal.

En Gordoncillo, el SNT tuvo tempranamente la panera que nos ocupa, aunque con una peculiaridad: el edificio fue compartido. Así, la planta baja era la que utilizaba el SNT como granero, cuya capacidad era de $9.200 \mathrm{~m}^{3}$ de trigo ${ }^{39}$. Allí los agricultores llevaban su producción intervenida y los molineros recogían sus cupos para molturar ${ }^{40}$. La planta superior, doblada gracias a un forjado de madera, servía como almacén a la fábrica de harinas «Marina Luz», motivo por el cual se accedía a ella desde una escalera practicada en el patio interior existente entre la fábrica y la panera. La entrevista realizada al molinero Raimundo Tejedor nos corroboró esta doble función del edificio. Lo que no tenemos realmente claro es quien mandó construir la panera, el SNT o Germán García Luengos, dueño de la harinera, o si ambas partes llegaron a un acuerdo y lo hicieron conjuntamente, ya que la fecha de

\footnotetext{
${ }^{36}$ Deben tenerse en cuenta los cambios de siglas a lo largo del tiempo: en 1968 el SNT pasa a denominarse Servicio Nacional de Cereales (SNC) y en 1971 Servicio Nacional de Productos Agrarios (SENPA).

${ }^{37}$ Veinte años de Actuación, obra editada por el SNT en 1958.

38 BARCIELA LÓPEZ (1981) p. 726 y ss.

39 PRIETO LÓPEZ (2007). Historia de la villa... tomo II, p. 295.

40 De ello sólo tenemos testimonios orales y alguna evidencia documental: diversos fragmentos con textos del SNT adheridos a las paredes interiores de la propia panera.
} 
construcción de la fábrica y la panera se estima muy cercana ${ }^{41}$. Los constructores de dicho edificio fueron Aquilino Peña y su hijo Honorio Peña, naturales y residentes en Matanza de los Oteros. Ambos levantaron una panera al estilo tradicional, con fuertes muros de tapial.

\subsection{El empresario Germán García Luengos}

Detrás de la instalación de la fábrica de harinas «Marina Luz» se encuentra una personalidad destacada a nivel local, Germán García Luengos, cuya principal actividad profesional fue la medicina ${ }^{42}$. En Gordoncillo sabemos que en 1924 ejercía como médico de esta localidad ${ }^{43}$. El 17 de junio de 1944 el Ayuntamiento le nombró médico para la asistencia pública domiciliaria ${ }^{44}$. Hemos observado también que en buena parte de los documentos que enviaba como industrial harinero utilizaba el papel timbrado propio de su profesión. Gracias a ello conocemos que en 1957 tenía una consulta médica en León, avenida Padre Isla número 11, piso segundo ${ }^{45}$.

Desarrolló también una breve actividad política. Durante la dictadura de Primo de Rivera fue proclamado alcalde de Gordoncillo, como presidente de una Comisión Municipal Permanente, el 3 de abril de $1924^{46}$. Desconocemos los motivos que provocaron su ausencia en la sesión que le nombró, lo cierto es que su toma de posesión se produjo de facto en la sesión siguiente -6 de abril-, en la que se le hizo entrega del bastón y sello de alcalde ${ }^{47}$. García Luengos ocupó la alcaldía durante cinco meses, ya que el 6 de septiembre de 1924 presentó su dimisión, alegando falta de tiempo para desempeñar su profesión. A raíz del nombramiento interpretamos que Germán García Luengos tenía relación con el órgano local de la

${ }^{41}$ En el Ayuntamiento de Gordoncillo nos informaron que la fecha de construcción de la panera era el año 1937. Esta misma datación aparece en un folleto promocional del municipio: Gordoncillo (2003). Sin embargo, el molinero Raimundo Tejedor opinaba que sería posterior a 1937, algo que también pensamos nosotros, ya que nos parece una fecha muy temprana habida cuenta de que el propio SNT se crea el 23 de agosto de 1937.

42 Según testimonios orales, obtuvo la plaza de médico en la localidad de Mayorga de Campos (Valladolid), pero renunció a ella.

43 AMG. Folio exento insertado entre las hojas 35 y 36 del tomo $13^{\circ}$ de los libros de sesiones.

44 AMG. Libros de sesiones, 1944.

45 AHPL. R.I. 2356. Expediente $n^{\circ}$ 2163. Caja 2598.

${ }^{46}$ AMG. Libros de sesiones, tomo $13^{\circ}$, folios 23, 24 y 25. Sesión extraordinaria del 3 de abril de 1924.

${ }^{47}$ Ibídem, tomo $13^{\circ}$, folio 25 (vuelto). Sesión ordinaria del 6 de abril de 1924. 
La industria harinera en la provincia de León durante el franquismo: la fábrica de harinas...

Unión Patriótica, partido único del directorio primorriverista que solía nutrirse de las élites económicas.

Del breve mandato municipal de Germán García destaca un acuerdo importante, la contratación del alumbrado público de Gordoncillo ${ }^{48}$. Para ello, en la sesión del 23 de julio de 1924 se acordó establecer contacto con los responsables de la hidroeléctrica de Valderas, negociaciones que se encomendaron al propio alcalde ${ }^{49}$. La Central Eléctrica de Valderas ${ }^{50}$ pertenecía en aquellos momentos a Ángel Izquierdo, el baratillero, a quien García Luengos había comprado o compraría el molino que ya mencionamos. No es baladí este hecho, puesto que también favorecerá a la instalación de la harinera, ya que la línea eléctrica hasta Gordoncillo establecerá el último transformador junto al molino maquilero, lo que facilitará el abastecimiento de la futura fábrica.

La llegada de la electricidad no se produjo durante el mandato de Germán García Luengos, ya que dos sesiones después de su renuncia a la alcaldía el pleno del Ayuntamiento apremió a Ángel Izquierdo para que procediera lo antes posible a dar luz a la población ${ }^{51}$. Por fin, en 1925 parece que quedó definitivamente instalada la red, ya que entre los acuerdos tomados por la corporación encontramos gastos para material eléctrico de las escuelas ${ }^{52}$ y la adquisición de 54 lámparas para el alumbrado público ${ }^{53}$. La construcción del último transformador de luz fue aprobada en el pleno municipal celebrado el 17 de mayo de 1936, previa solicitud del terreno por parte de la Central Eléctrica de Valderas, que ya por entonces había cambiado de dueño, siendo entonces propiedad de Eduardo Pitarch Renau ${ }^{54}$.

${ }^{48}$ La Central Eléctrica de Valderas había solicitado autorización en 1916 para llevar una línea hasta Gordoncillo, pero no debió llevarse a cabo hasta 1925, lo que es sorprendente pues núcleos como Valderas o Valencia de Don Juan ya disponían de alumbrado en sus calles desde 1898: GARCía ABAD (1968). Historia de Valderas..., p. 247 y GARCía FERnÁNDEZ (1948). Historia de la villa de Valencia..., p. 273.

${ }^{49}$ AMG. Libro de actas..., tomo $14^{\circ}$, folio 7.

${ }^{50}$ Producía energía eléctrica gracias a un salto de agua artificial creado en el río Cea, ubicado en el pago "las nieblinas", al noroeste del núcleo urbano de Valderas. La concesión del aprovechamiento hidráulico de dicho salto data de 1911, y fue dada a la sociedad Marino, Valcarce y Diéguez.

${ }^{51}$ AMG. Libro de actas..., tomo $14^{\circ}$, folio 12.

52 Ibídem, folio 24. Sesión extraordinaria del 13 de mayo de 1925.

53 Ibídem, folio 29. Sesión ordinaria del 5 de agosto de 1925.

54 AMG. Libros de sesiones, tomo 20º folio 9. Sesión ordinaria del 17 de mayo de 1936. Apuntamos también que con fecha 5-VII-1936 finalizó el contrato de suministro de alumbrado público para la Central Eléctrica de Valderas, y que desde el 23-IV-1938 el fluido eléctrico lo proporcionó la sociedad El Porvenir de Zamora. Desde el 11 de junio de 1941 la energía eléctrica que 
Germán García Luengos dejó su huella en el ámbito económico de Gordoncillo $^{55}$, no sólo como dueño de la fábrica de harinas «Marina Luz», sino en otros negocios e industrias: tahona o panadería, fábrica de quesos, bodega de $\operatorname{vinos}^{56}$, carnicería y alcoholera ${ }^{57}$.

\subsection{La harinera entre 1936 y 1945}

A pesar de la clara alusión a la fábrica de harinas en el acta municipal del 2 de abril de 1933 que solicitó la construcción de las escuelas públicas, existe una referencia posterior -7 de julio de 1934- que niega la existencia de fabricantes de harinas en la villa. Ante ello y en virtud de un decreto del Ministerio de Agricultura se procedió al nombramiento de una Junta Local de Contratación de Trigo ${ }^{58}$. Esto puede parecer una contradicción, pero creemos que la razón debe ser que en aquellos momentos la fábrica de harinas de Germán García Luengos estaba en construcción o instalación. No debe sorprendernos un periodo tan largo, puesto que por otras harineras conocemos los frecuentes retrasos en el suministro del utillaje.

Debido a la carencia absoluta de datos escritos sobre el origen de la industria ${ }^{59}$ recurrimos a los testimonios orales, siéndonos especialmente valiosa la información que nos facilitó el ya citado Raimundo Tejedor. Él nos aseguró que la fábrica inició su actividad en el año 1936 y que el técnico encargado de su montaje fue Félix Agüera, quizás oriundo de Palencia, que continuó su actividad en Simancas (Valladolid).

llegaba al municipio de Gordoncillo procedía de la Central Hidroeléctrica del Cea, instalada en Benavente (Zamora) y propiedad de Juan Otero Colino [AMG, Contrato de alumbrado público].

55 Según la documentación del AMG, fue el mayor contribuyente industrial de la villa de Gordoncillo, al menos, en los años 1941 y 1942, y el mayor contribuidor por suelo urbano en 1943 y 1944. Como curiosidad, apuntar que el 26 de diciembre de 1936 el Ayuntamiento le abonó 156 pesetas para reparar su automóvil, ya que siendo usado por los miembros de la corporación había sufrido desperfectos. Debía ser por entonces uno de los pocos vehículos autopropulsados de la localidad.

${ }^{56}$ Cuya actividad han continuado sus herederos en la actual Bodegas Villacezán, S.L.

${ }^{57}$ La Sociedad Alcoholera de Gordoncillo documentada desde 1925 [ACOCIL. Libro de Censo Electoral. 1925] y que en origen tenía 78 socios [Domínguez De VALDEón (1925). El libro de Valderas..., p. 45] será adquirida posteriormente por Germán García Luengos.

${ }^{58}$ AMG. Libros de sesiones, tomo 19º pág. 85. Sesión ordinaria del 7 de julio de 1934: ...por no haber en la localidad fabricantes de harinas ni compradores de trigo...

59 A partir de ahora la fuente fundamental de nuestra investigación es un expediente del AHPL [R.I. 2356, Signatura 2163, Caja 2598], que nos ofrece datos desde abril de 1941. Buscando referencias anteriores acudimos a los libros del censo de la Cámara Oficial de Comercio e Industria de León, pero nos informaron que se habían perdido los comprendidos entre 1928 y 1957, ambos años inclusive. 
Como se hizo en muchos casos, el nombre de la fábrica de harinas se tomó de la mujer del empresario, en este caso llamada Marina Luz Alonso Alonso. Hay que tener en cuenta que las harineras siempre eran "bautizadas" con alguna denominación, bien referida a sus dueños (como este caso), bien a otras características (emplazamiento, producción) o identificadores (promocionales, religiosos).

Tenemos constancia de que la harinera molturaba ya, al menos, a finales de 1936, pues en el semanario Prisma de Valderas, dirigido por Antonio González de Lama $^{60}$, encontramos un anuncio publicitario de la misma desde el 29 de noviembre ${ }^{61}$ que indica "se efectúan las operaciones en forma de cambio", lo que en otros documentos se denomina canje. Estamos inmersos en un contexto económico autárquico, con el pan sometido al racionamiento ${ }^{62}$ y con la obligatoriedad de entregar al Estado una parte importante de la cosecha de cereales $^{63}$. El agricultor se reservaba el resto de su producción como simiente futura y para el autoconsumo humano y ganadero, por lo que, dado que dichos cereales no podían consumirse como tal, la legislación permitía a los agricultores el “canje” por harina o pienso en molinos maquileros o fábricas autorizadas.

Ni que decir tiene que ello ocasionó numerosas molturaciones clandestinas y un gran mercado negro, que la dictadura intentó frenar recurriendo a cierres temporales de los molinos $^{64}$ o a la coacción $^{65}$, acciones en buena parte

${ }^{60}$ Editaba Prisma desde 1926, mérito que le valió para tomar la dirección de El Diario de León entre 1937 y 1939: RoDRíGUEZ GONZÁLEz (2003). León bajo la dictadura franquista... p. 180, nota 333.

61 Como indicamos, el primer anuncio publicitario de la Fábrica de Harinas «Marina Luz» aparece en el n 10 con fecha 29-XI-1936 y desaparece de sus páginas el 31-VII-1938. Situado en la contraportada del semanario, el anuncio menciona, además del nombre y la dirección, la frase "Se efectúan las operaciones en forma de cambio". Hay que indicar además que hasta el 7-II-1937 por errata se dice "María-Luz" en lugar del nombre correcto "Marina-Luz". Agradecemos a Niceto Tirados que pusiera a nuestra disposición su archivo personal, en el que conserva la mayoría de ejemplares de este periódico valderense.

62 El racionamiento del pan concluyó en marzo de 1952: FeRnÁNDEZ FernáNDEZ (2003). El franquismo en la provincia de León... p. 179.

63 Para conocer cómo se establecían los cupos de entrega forzosa de cereales ver Ibídem, p. 185. La producción intervenida debía ser transportada a la panera más cercana: RoDRíGUEZ GoNZÁLEZ (2003). o.c., pp. 273-274.

64 El SNT clausuró los molinos leoneses, al menos, en los años 1947 y 1959: FERNÁNDEZ FERNÁNDEZ (2003). o.c., p. 186.

${ }^{65}$ La ocultación de cereal y su mercado clandestino se llegó a considerar delito de auxilio a la rebelión: RODRÍGUEZ GONZÁLEZ (2003): o.c., p. 62. 
propagandísticas, pues muchos cargos públicos se lucraron con el estraperlo, siendo más que habituales la corrupción y el clientelismo ${ }^{66}$.

La fábrica de harinas «Marina Luz» de Gordoncillo era una de las autorizadas a cambiar cereales por harina, era una harinera de cupo y canje. La burocratización era total, puesto que la capacidad de molturación era designada por la Dirección General de Industria, mientras que el SNT aportaba la correspondiente materia prima del total de las cosechas de la zona, intervenidas forzosamente por el Nuevo Estado. Posteriormente era la Comisaría General de Abastos quien asignaba los cupos de harinas a las provincias y los municipios.

En referencia a las características técnicas de la fábrica inicial hemos de indicar que esta no ha llegado físicamente hasta nuestros días debido a un incendio que la destruyó completamente en 1944, por lo que los datos de que disponemos son limitados a la documentación existente. Por un acta de comprobación y autorización de puesta en marcha de 1945 conocemos que la fábrica contaba en la sección de molienda con tres molinos dobles de $400 \mathrm{~mm}$ marca Hispania ${ }^{67}$, que proporcionaban una longitud trabajante de 2,40 metros, y que realizaban tres pasadas de trituración y tres de desagregación, ninguna de compresión.

No tenemos otras referencias relativas al resto de máquinas de limpia y cernido. Sobre la disposición del primitivo edificio fabril los testimonios orales nos indican que era similar al actual, en tres pisos: sótano (más reducido), bajo y primera planta. Sabemos también que en principio las puertas y ventanas del edificio principal daban salida a la calle Real.

Tras los primeros años de fabricación debieron manifestarse defectos en el proceso de transformación, ya que la harina resultante ofrecía partículas gruesas de salvado $^{68}$. Ante ello el 28 de abril de 1941, Germán García Luengos solicitó a la Delegación de Industria de León (en adelante, DIL) permiso para realizar obras de reparación en las que invertiría un capital de 3.000 pesetas e instalaría "un molino sencillo de una pasada de 500, que realizará el trabajo de desagregador”. La

${ }^{66}$ Ibídem, pp. 371-375. Nosotros conocemos testimonios orales según los cuales la mejor harina salida de la fábrica «Marina Luz» se reservaba para elaborar un exquisito pan blanco con el que se agasajaba a Carlos Arias Navarro, gobernador civil de León entre 1944 y 1949, en sus cacerías por el sur de la provincia.

${ }^{67}$ Otras referencias a este sistema de molturación se constatan en una fábrica de Pesquera (Cantabria): Ansola y Sierra (2007). Caminos y fábricas... y en otra de Mota del Marqués (Valladolid): CARRERA DE LA RED (1990). Las fábricas de harina..., p. 131.

68 AHPL. R.I. 2356. Expediente $n^{\circ}$ 2163. Caja 2598. Memoria firmada por Germán García Luengos el 28 de abril de 1941. 
solicitud será denegada por el Ingeniero Jefe de la DIL el 6 de mayo de 1941, ya que entendía que "supone un aumento en la línea de trabajo y por tanto en la capacidad de producción”, para lo cual no poseía las licencias oportunas.

Con posterioridad, García Luengos presentó una nueva memoria solicitando "la instalación de un molino sencillo de una pasada, de 500, que realice el trabajo de remolido de subproductos de molinería en la fábrica de harinas”. En esta ocasión la inversión se prevé en un total de 8.000 pesetas $^{69}$. Entonces se aceptó la solicitud, precisando que la actuación no aumentaba la capacidad de molturación de la fábrica. El 3 de agosto de 1942 la DIL comunicó la concesión, aunque Germán García tuvo que solicitar una prórroga que aumentara el mes de plazo que se fijó para la instalación de la máquina "ya que no he podido lograr que el montador se encargue antes de esa fecha de realizar los correspondientes trabajos". Con la instalación de este molino sencillo de $500 \mathrm{~mm}$ se alcanzaba una longitud trabajante de 2,90 metros, según datos de la DIL.

La harinera de Gordoncillo sufrió un incendio en 1944. Sin duda el fuego constituyó el principal peligro para las fábricas de harinas hasta la implantación de eficientes normativas de seguridad. En el periodo que nos encontramos existían muchos factores que favorecían los incendios en este tipo de factorías:

- la abundancia de elementos de madera que conformaban la maquinaria y los edificios de aquella época

- los elevadores de cangilones, cañas y tubos de madera recorrían de arriba abajo todo el edificio fabril y, en caso de fuego, actuaban como chimeneas

- las precarias instalaciones eléctricas, sometidas a frecuentes cambios de tensión y cortes de suministro, provocaban frecuentes cortocircuitos

- el polvo de harina en suspensión creaba una atmósfera en el interior de la fábrica altamente inflamable

No debemos olvidar tampoco los incendios provocados intencionadamente ante su fácil combustión. Con todos estos factores se explica que tantas fábricas de harinas fueran pasto de las llamas durante los siglos XIX y XX. Así sucedió con «Marina Luz» durante la noche del 5 al 6 de marzo de 1944, noticia recogida por el corresponsal del Diario de León:

${ }^{69}$ Ibídem. Memoria del 16 de junio de 1942. 
En el pueblo de Gordoncillo se declaró un violento incendio en una fábrica de harinas, propiedad de don Germán García Luengos. Al parecer el fuego se debió a un cortocircuito y desde los primeros momentos tomó grandes proporciones. Acudieron a sofocarle los obreros de la empresa y puede decirse que todo el vecindario de Gordoncillo, consiguiendo extinguirle horas después. Las pérdidas se calculan en unas ciento cincuenta mil pesetas $^{70}$

Tras la destrucción de su fábrica Germán García solicitó que de manera temporal, hasta que la industria pudiera estar operativa de nuevo, se le diese licencia para moler cereal panificable en un molino. Sin embargo, la legislación vigente ya no permitía los molinos que molturasen en régimen de fábrica, por lo que su petición fue rechazada el 23 de junio de 1944, aunque el SNT informó favorablemente sobre la reconstrucción de la fábrica siniestrada.

Más de un año después del incendio, el 15 de mayo de 1945 Germán García Luengos remitió una solicitud a la DIL para reabrir su fábrica de harinas "para con ello atender las necesidades que venía satisfaciendo del abastecimiento de harinas de cupo y canje”. Adjuntó una memoria que reflejaba la inversión necesaria "de doscientas cincuenta a trescientas mil pesetas, propias y de crédito”, estimaba en ocho el número de empleados y obreros a colocar y establecía que la fabricación de harinas sería de 4.500 a 5.000 kilogramos al día. Además aportó una relación valorada de máquinas y elementos a instalar en la nueva industria (Tabla 1).

La solicitud se admitió y la autorización fue publicada en el Boletín Oficial de la Provincia de León número 168 del 30 de julio de 1945. El diseño, planificación e instalación de la nueva fábrica, aunque en el mismo emplazamiento y sobre los restos del edificio de la anterior, se encargó esta vez a la casa Bühler, empresa suiza fabricante de todo tipo de maquinarias y accesorios destinados a la molturación de alimentos ${ }^{71}$. Para el proyecto de Gordoncillo, Bühler realizará a

${ }^{70}$ Diario de León, 11-III-1944, p. 3. También lo referenciaron el periódico Proa el 11-III-1944, p. 5 y la revista Molinería y Panadería, número 409 de abril de 1944, que indica además "estar mal asegurada, en relación con el precio que le ha de costar ahora si la quiere reponer”.

${ }^{71}$ Adolf Bühler montó una fundición de hierro en Uzwill (Suiza) hacia 1860, en la que recibió numerosos encargos de molinos de cilindros, por lo que en 1876 decidió desarrollar la industria que verdaderamente le daría fama mundial. Bühler dispuso de una delegación en España desde finales del siglo XIX, primero con sede en Barcelona (situada en la Rambla de Cataluña) y finalmente en Madrid (en 1917 sus anuncios publicitarios remiten a la calle de Atocha, 36. A finales de los años 1930 se ubicaba en la calle San Sebastián, 2. Actualmente se encuentra en el polígono industrial "Las Arenas" de la ciudad de Pinto). En nuestro país tenía la razón social Bühler, S.A., por lo que su producción constaba oficialmente como de origen español, lo que facilitó a esta empresa el diseño e instalación de numerosas fábricas de harinas en todo el territorio estatal durante la autarquía. 
nombre de Germán García Luengos inicialmente 5 planos a escala 1:50, numerados del 10.224 al 10.228 y fechados el 29 de noviembre de $1944^{72}$. Con posterioridad estos mismos planos sufrieron varias modificaciones, variando algunas máquinas, el nombre del titular -que pasó a ser Harino-Panadera de Gordoncillo, S.L.- y su numeración, ahora del AEMT-83419 al AEMT-83423. Decir también que otros tres planos numerados del AEMT-83342 al AEMT-83344 se crearon más adelante para la fábrica de Gordoncillo con el objetivo de adosar un silo e incorporar un sistema de ante-limpia ${ }^{73}$.

Tabla 1. Estimación de bienes de equipo para la nueva fábrica

\begin{tabular}{|c|c|c|}
\hline Número & Máquinas & Valor \\
\hline 3 & Molinos de 500 × $220 \mathrm{~mm}$ & 39.000 ptas. \\
\hline 1 & Deschinadora de seis calles & 5.000 ptas. \\
\hline 1 & Desatador & 500 ptas. \\
\hline 1 & Afinador adelantador de molienda & 2.800 ptas. \\
\hline 1 & Despuntadora-Satinadora & 8.200 ptas. \\
\hline 1 & Cepilladora de salvados & 3.800 ptas. \\
\hline 1 & Torno divisor de clases & 2.500 ptas. \\
\hline 1 & Monitor & 6.000 ptas. \\
\hline 1 & Triarvejón & 3.000 ptas. \\
\hline 1 & Separador de semillas (tobogán) & 600 ptas. \\
\hline 1 & Rociador automático & 1.750 ptas. \\
\hline 1 & Aspirador & 2.800 ptas. \\
\hline 1 & Recolector de polvos & 2.500 ptas. \\
\hline 1 & Sasor doble & 10.000 ptas. \\
\hline 1 & Plansichter seis canales & 8.000 ptas. \\
\hline 1 & Torno de seguridad & 1.500 ptas. \\
\hline 2 & Distribuidores & 1.200 ptas. \\
\hline 10 & Elevadores y dos roscas & 18.975 ptas. \\
\hline- & Accesorios & 15.000 ptas. \\
\hline- & Poleas y transmisiones & 9.000 ptas. \\
\hline 1 & Motor eléctrico 25,80 HP & 8.000 ptas. \\
\hline
\end{tabular}

Fuente: AHPL, R.I. 2356

La instalación de la nueva fábrica de harinas «Marina Luz» concluyó en septiembre de 1945, ya que entonces el ingeniero de la DIL, Carlos Sánchez Román, levantó acta de comprobación y autorización de puesta en marcha, en la que se señaló que la longitud trabajante instalada era de 3 metros, superior a los 2,9 que poseía la fábrica antes del incendio, y constató la siguiente maquinaria:

Planta baja.- Motor de $19 \mathrm{Kw}$ con su cuadro y transmisión general, 1 deschinadora de 6 calles, 1 afinador-adelantador de molienda, 1 desatador, parte inferior de los elevadores y la recogida de residuos de limpia.

\footnotetext{
${ }^{72}$ AHPL. R.I. 2356. Expediente n ${ }^{\circ}$ 2163. Caja 2598. Los planos se conservan por duplicado.

73 Bühler, S.A. conserva estos planos microfilmados en su archivo de Pinto (Madrid).
} 
Parte intermedia.- 3 molinos dobles Buhller (sic) de $500 \mathrm{~m} / \mathrm{m}, 1$ cepilladora de salvados, 1 tobogán, 1 despuntadora-satinadora, 1 ventilador para la limpia, 2 mezcladoras y la parte baja de los tres depósitos de reposo.

Parte alta.- Un centrífugo de 2 metros, 1 planchister (sic) doble de 6 calles, 1 sasor doble, un recolector de 120 mangas, 1 ventilador-aspirador, 1 triarbejón [sic], 1 monitor, parte alta de los depósitos de rociado, 1 ciclón, 1 depósito de agua y parte alta de los elevadores. En local aparte y contiguo, 1 divisor de salvados y el empaque de las harinas y salvados ${ }^{74}$

En 1945 encontramos una contradicción en los datos que manejan el SNT y la DIL. Para el primero, la capacidad de molturación que poseía la Fábrica de Harinas «Marina Luz» a fecha 25 de septiembre de 1945 era de 4.700 kg/día, mientras que la segunda, tan sólo 4 días después, informó que la capacidad era de $4.291 \mathrm{~kg} /$ día. Como vemos, la compleja burocratización además de ralentizar los procesos provocaba discrepancias entre los distintos órganos competentes, lo que ocasionaba múltiples problemas.

\subsection{La sociedad Harino-Panadera de Gordoncillo}

La nueva fábrica de harinas instalada por Bühler será gestionada directamente por Germán García Luengos hasta el 31 de diciembre del año 1947, fecha en que ante notario ${ }^{75}$ se procedió a la Constitución de la Sociedad Mercantil de Responsabilidad Limitada "Harino-Panadera de Gordoncillo", que estaba formada por el propio Germán y por sus hijas Abilia, María Victoria y María Jesús García Alonso. Cada socio aportó 25.000 pesetas, por lo que el capital social de la nueva empresa fue de 100.000 pesetas.

Según el artículo segundo de la escritura de constitución “el objeto de la Compañía será el de fabricación y comercio de harinas, cereales y sus derivados, elaboración de pan, así como molturación de piensos, pudiendo dedicarse a cualquier otra clase de operaciones de lícito comercio, que se estimen necesarias o convenientes”. El artículo undécimo indicaba que la gerencia de la compañía sería nombrada de común acuerdo por los socios ${ }^{76}$.

Una de las primeras gestiones de la sociedad Harino-Panadera de Gordoncillo, S.L. fue el arriendo de la fábrica de harinas «Marina Luz» a su propietario, Germán García Luengos. Para ello elevó instancia a la DIL el 17 de mayo de 1948. El

74 AHPL. R.I. 2356. Expediente n ${ }^{\circ}$ 2163. Caja 2598. “Acta de comprobación y autorización de puesta en marcha”. Salida DIL: 19-IX-1945.

75 Manuel Crehuet Juliá (Valderas).

${ }^{76}$ El primer gerente fue Isidro Gutiérrez García. 
arrendamiento fue aceptado el 28 de octubre de 1948, indicándose que dicho traspaso por arriendo se hacía en base a los mismos elementos con que constaba la fábrica anteriormente, en clara referencia a la capacidad de molturación asignada.

Para tratar de "suplir las frecuentes y grandes restricciones de energía eléctrica que anualmente viene sufriendo esta industria, y con ello poder atender debidamente al abastecimiento provincial de harinas”, el gerente Isidro Gutiérrez solicitó a la DIL el 1 de octubre de 1949 la instalación de un motor "Diesell-40 H.P., de los que ha de importar el Ministerio de Industria y Comercio"77. La inversión en esta nueva fuente de energía “a Gas-oil” supondría el desembolso de 60.000 pesetas, y el plazo de puesta en marcha se fijó en dos meses. El 29 de noviembre de 1949 el Jefe Provincial del SNT comunicó su opinión favorable, lo que llevó a la DIL a aceptar la solicitud el 4 de enero de 1950. Sin embargo, entre las relaciones de maquinaria posteriores a esta fecha nunca aparecerá este motor, por lo que seguramente no se llegara a instalar. De todos modos lo que nos interesa es el hecho que provocó la petición: los problemas en el suministro de energía eléctrica a finales de los años cuarenta, que paralizaban frecuentemente la producción industrial $^{78}$, y el obligatorio papel del Ministerio como intermediario entre las industrias españolas y las extranjeras para la adquisición de bienes de equipo.

Mejoras más importantes serán las que introduzcan los proyectos modificados realizados por Bühler, S.A. y cuyos planos ya citamos al hablar de la reconstrucción. Sin que se indique la fecha en que tuvieron lugar, lo cierto es que sustituyen los tres molinos Bühler de $500 \mathrm{~mm}$ por otros tantos del modelo $D D K b$, también Bühler, de $600 \mathrm{~mm}$. Además se incorporó un cuarto molino de $500 \mathrm{~mm}$, en línea con los anteriores y ocupando el lugar de la cepilladora. En la planta de transmisiones se sustituyeron el desatador y el afinador por dos cepilladoras Bühler modelo $M K K a$, y en la planta superior se incorporó una máquina sin especificar, pero que debió ser una centrifugadora, ya que su ausencia había sido apreciada en los planos originales por medio de una anotación manuscrita.

\footnotetext{
${ }^{77}$ Aquí se pone de manifiesto otro de los problemas que ocasionaba la autarquía, al no permitir la libre compra de máquinas en el extranjero.

78 “...decían cuando la guerra «ni un hogar sin pan», pues muy bien... ¡sin luz!, hubo restricciones a la una o las dos de la noche que se apagaba la luz e igual no volvía hasta las ocho de la mañana (ríe) pues ponía de estar sin pan... ¡se pasó más hambre!, nosotros no eh, los que trabajábamos allí teníamos derecho a 740 gramos de harina para elaborar un kilo de pan..." testimonio de Raimundo Tejedor Velado.
} 
El 6 de octubre de 1950, el Ingeniero Jefe de la DIL, Antonio Martín Santos, autorizó la puesta en marcha de la instalación fabril ${ }^{79}$. Debemos entender, por la fecha, que dicha autorización se refiere a la nueva modificación de la fábrica y no al proyecto de reconstrucción. Sorprende que en el expediente conservado en el Archivo Histórico Provincial de León no existan referencias de estas modificaciones, pero los planos no dejan lugar a la duda ya que descartamos que la fábrica permaneciera inactiva desde el incendio, pues los testimonios orales nos aseguran que molturó desde finales de 1945.

Tampoco existe reflejo documental -salvo en las planimetrías de Bühler- del nuevo edificio anexo a la fábrica que incorporó una ante-limpia y un silo para el trigo. Esta construcción se ubicaba junto a la fábrica, a la derecha si tomamos como referencia la entrada principal al edificio fabril, avanzándose unos metros a la línea de fachada principal de este. En su interior se diferenciaban claramente dos partes:

- Silo de planta cuadrada y perfil en forma de pirámide invertida. Estaba subdivido en nueve cubículos cuadrados en líneas de tres. Se situaba inmediato a la fábrica.

- Ante-limpia con la siguiente maquinaria: roscas-elevadores, ciclón, separador, aspirador y tres motores, además de una tolva por la que se introducía el cereal.

Este edificio no se ha conservado, ni hemos podido localizar fotografías del mismo.

Pero sin duda, la gestión más importante será la relacionada con la ampliación de la capacidad de molturación de la fábrica de harinas «Marina Luz», un proceso largo y complejo. El nuevo proyecto fabril de Harino-Panadera de Gordoncillo, S.L. se propuso alcanzar los 4,6 metros de longitud trabajante, teniendo únicamente derechos para los 2,9 m que poseía la fábrica antes del incendio de 1944. La única manera de aumentar la capacidad productiva era comprar derechos a otro empresario o sociedad que estuviese en disposición de venderlos, consiguiendo además el beneplácito de las autoridades para su traslado.

Primera compra de derechos: Miranda de Ebro (Burgos). El 22 de julio de 1955 un incendio destruyó la fábrica de harinas «La Flor de Miranda» ${ }^{80}$, instalada en la

${ }^{79}$ AHPL. R.I. 2356. Expediente $n^{\circ}$ 2163. Caja 2598.

80 OJeda SAN Miguel (2001). Estudios de historia..., pp. 175-221 recoge las harineras mirandesas e indica que concretamente esta se incendió en la década de 1950. Sus restos se encuentran junto al cerro de La Picota. Fue creada a finales del siglo XIX por la sociedad Ubierna, Espeso y Cía., y reconstruida ya en el siglo XX por Adolfo Verduras San Miguel. 
indicada ciudad burgalesa, y su propietario no se planteó su reconstrucción. Germán García Luengos adquirió personalmente su cupo productivo: 4,1 metros de longitud trabajante -equivalentes a una capacidad de molturación de 8.200 kilogramos de trigo en 24 horas- y lo inscribió en la Delegación de Industria de Burgos. El 17 de enero de 1956 solicitó su traslado a León "con el fin de unificar y ampliar la industria harinera que explota en tal provincia”. El 23 de febrero el Ingeniero Jefe de la DIL comunicó a su superior, el Director General de Industria, que "aunque en ambas provincias hay un exceso de capacidad de molturación, esta es mucho mayor en la de Burgos que en la de León y quizás pudiera ser interesante hacer que esta diferencia disminuyera”. Con ello, desde Madrid se autorizó el traslado el 7 de marzo de 1957, estableciendo tres meses como plazo máximo para hacerlo efectivo. La autorización de la Dirección General de Industria se acompañó de una relación de la maquinaria existente en Miranda de Ebro, no para efectuar su traslado físico -pues quedó inservible en el incendio- sino como justificante de los derechos adquiridos. Nuevamente existen discrepancias entre los inventarios de diferentes oficinas, como vemos en la Tabla 2.

Tabla 2. Utillaje (derechos) adquirido en Miranda de Ebro (Burgos)

\begin{tabular}{|c|c|c|c|}
\hline \multicolumn{2}{|c|}{ Según la Dirección Gral. de Industria (7/3/1957) } & \multicolumn{2}{|c|}{ Según la Delegación de Indus. de Burgos (27/3/1957) } \\
\hline Cant. & Maquina & Cant. & Máquina \\
\hline 1 & $\begin{array}{l}\text { Lavadora de trigo hidro-extractora, } \\
\text { marca ROBINSON }\end{array}$ & 1 & Deschinadora de 6 calles, marca PASCUAL \\
\hline 1 & Deschinadora de 4 calles, marca PANÉ & 1 & Triarvejón Rápido \\
\hline 1 & Monitor & 1 & Tobogán \\
\hline 1 & Triarvejón & 1 & Cepilladora de trigo, marca MORROS \\
\hline 1 & Despuntadora & 1 & Rociador automático \\
\hline 1 & Satinadora & 1 & Lavadora hidro, marca ROBINSON \\
\hline 1 & Ciclón & 3 & Molinos de 700x230 mm, marca MORROS \\
\hline 2 & Aspiradores & 1 & Molino de 600x230 mm, marca MORROS \\
\hline 1 & Recolector de polvos de 64 mangas & 1 & $\begin{array}{l}\text { Plansichter de } 6 \text { entradas y } 16 \text { tamices, } \\
\text { marca MORROS }\end{array}$ \\
\hline 1 & Electromotor de $10 \mathrm{CV}$ & 1 & Sasor, marca DAVERIO \\
\hline 1 & Rociador automático & 1 & Ventilador \\
\hline 3 & $\begin{array}{l}\text { Molinos dobles de 500x190 mm., marca } \\
\text { PANÉ }\end{array}$ & 1 & Recolector de 280 mangas \\
\hline 1 & $\begin{array}{l}\text { Molino doble de 400x200 mm., marca } \\
\text { MORROS }\end{array}$ & 1 & Torno clasificador de salvado \\
\hline 1 & Sasor doble, marca PANÉ & 1 & Mezcladora \\
\hline 1 & Plansichter de 10 entradas & 3 & Desatadores \\
\hline 1 & Recolector de polvos de 72 mangas & 1 & Monitor, marca ROBINSON \\
\hline 1 & Torno divisor de salvados & & \\
\hline 1 & Torno centrífugo & & \\
\hline 1 & Electromotor de $15 \mathrm{CV}$ & & \\
\hline 1 & Turbina hidráulica & & \\
\hline- & $\begin{array}{l}\text { Roscas, elevadores, transmisiones y } \\
\text { demás elementos accesorios propios de } \\
\text { la industria. }\end{array}$ & & \\
\hline
\end{tabular}

Fuente: AHPL, R.I. 2356 
A petición del SNT y de la Dirección General de Industria, se realizó en aquellos momentos una Revisión del Censo de la Industria Harinera a la fábrica «Marina Luz» de Gordoncillo "con objeto de establecer definitivamente las características de la mencionada fábrica, principalmente en lo que afecta a la longitud trabajante en cilindros”. Este informe entró en la DIL el 6 de mayo de 1957. En líneas generales el utillaje es prácticamente el mismo que quedó instalado entre 1945-1950 (Tabla 3).

Tabla 3. Inventario de bienes de equipo instalados en la fábrica de harinas «Marina Luz» de Gordoncillo a 6 de mayo de 1957

\begin{tabular}{|c|c|c|}
\hline Sección & Cant. & Máquina \\
\hline Molturación & 3 & $\begin{array}{l}\text { Molinos dobles DDKb-BUHLER, de } 600 \mathrm{~mm} \text {., números } 66.710,66.711 \text { y } 66.712 \text {. } \\
\text { Realizan el siguiente trabajo: tres pasadas de trituración de } 600 \mathrm{~mm} \text {. y tres pasadas } \\
\text { de compresión de } 600 \mathrm{~mm} \text {., con una longitud total trabajante equivalente a 3,60 } \\
\text { metros, equivalente a una Capacidad de Molturación de } 7.200 \mathrm{Kg} \text { en } 24 \text { horas. }\end{array}$ \\
\hline \multirow{12}{*}{ Limpia } & 1 & Monitor BUHLER, número 53.293 \\
\hline & 1 & Deschinadora BUHLER, 2.000 x 1.000 \\
\hline & 1 & Triarvejón rápido con alvéolos de 5,5mm. \\
\hline & 1 & Aspirador BUHLER, número 562 \\
\hline & 1 & Despuntadora BUHLER, número 35.245 \\
\hline & 1 & Rociador \\
\hline & 1 & Ciclón \\
\hline & 1 & Satinadora BUHLER, número 53.597 \\
\hline & 2 & Aparatos magnéticos \\
\hline & 1 & Distribuidor de trigo \\
\hline & 1 & Tobogán BUHLER \\
\hline & 1 & Esclusa de polvos BUHLER \\
\hline \multirow{8}{*}{ Cernido } & 1 & Plansichter BUHLER de 8 calles, número 9.622 \\
\hline & 1 & Sasor BUHLER \\
\hline & 1 & Torno separador de clases \\
\hline & 1 & Cepilladora de salvados, BUHLER \\
\hline & 2 & Desatadores, BUHLER \\
\hline & 2 & Mezcladoras, BUHLER \\
\hline & 1 & Recolector de polvos BUHLER, de 120 mangas \\
\hline & - & Superficie total de cernido: 32,16 metros cuadrados. \\
\hline & гга & $\begin{array}{l}\text { Aspirador RICO CUENCA } \\
\text { a eléctrica, potencia total } 40 \text { H.P. }\end{array}$ \\
\hline
\end{tabular}

Como la maquinaria burgalesa era inservible, para la ampliación la DIL solicitó a Germán García Luengos que comunicara los elementos que preveía instalar, a lo cual respondió el 18 de junio de 1957 con la relación de la Tabla 4.

Vistos los trámites anteriores, la Dirección General de Industria por medio de su delegación en León, autorizó el traslado el 5 de julio de 1957, dando un plazo de tres meses para configurar la nueva instalación. Pero nuevamente el plazo temporal le sería insuficiente a Germán García Luengos. Así, refleja que “no habiéndole 
servido la casa Buhler todo el material que se precisa para dicha obra y dadas las dificultades que dicha casa encuentra para servirlo en fecha fija, se hace indispensable la ampliación del plazo concedido”, solicitando un año más para concluir la instalación aprobada. De todos modos, no fue necesario un periodo tan amplio para ello ya que el 2 de septiembre de 1958 Germán García comunicó que la ampliación ya estaba totalmente terminada ${ }^{81}$.

Tabla 4. Maquinaria a instalar en la ampliación

\begin{tabular}{cl}
\hline Cant. & \multicolumn{1}{c}{ Elemento } \\
\hline 2 & Molinos dobles de 600x220, modelo Standar, marca DAVERIO \\
1 & Molino doble de 500x220, marca BUHLER \\
1 & Plansichter de 6 calles, marca DAVERIO \\
1 & Sasor sencillo, marca DAVERIO \\
1 & Despuntadora de $2.000 \mathrm{~kg} / \mathrm{h} .$, marca DAVERIO \\
1 & Satinadora de 2.000 kg/h., marca DAVERIO \\
1 & Cepilladora de salvado \\
1 & Torno centrífugo, marca BUHLER \\
- & Elevadores, roscas y demás útiles precisos para el buen funcionamiento de las máquinas \\
& apuntadas \\
\hline Fuente: AHPL, R.I. 2356
\end{tabular}

Venta de los derechos sobrantes: Valencia de Don Juan (León). El cupo adquirido por Germán García Luengos en Miranda de Ebro (4,1 metros) sumado al que poseía antes del incendio (2,9 metros) era superior al que quería alcanzar en su fábrica de Gordoncillo (4,6 metros de longitud trabajante). Por ello, sólo necesitaba incorporar 1,7 metros de los adquiridos en Burgos, sobrándole otros 2,4 metros de longitud trabajante. Así que los venderá el 17 de mayo de 1958 a "Hijos de Adolfo Sáez de Miera” para ampliar la capacidad de molturación de la fábrica de harinas «La Coyantina» situada en Valencia de Don Juan.

Sin embargo, con posterioridad a esta operación, la DIL tras consultar la Estadística de Molturación de Cereales y al SNT, rectificó a sus propietarios que la fábrica «Marina Luz» solamente tenía autorizada una longitud trabajante de 2’4 metros antes del incendio de 1944, por lo que redujo la nueva longitud actual ampliada a 4,1 metros. Ello obligó, nuevamente, a buscar vendedores de derechos de molturación para alcanzar los deseados 4,6 metros de longitud trabajante.

Segunda compra de derechos: Almagro (Ciudad Real). Germán García Luengos, que actuaba como gerente de Harino-Panadera de Gordoncillo, S.L., aunque también era socio, adquirió en este caso 560 milímetros de longitud trabajante que le vendió un industrial de Almagro, llamado Vicente Vicente Pérez. Fue operación compleja, puesto que el empresario almagreño había comprado el 22

${ }^{81}$ AHPL. R.I. 2356. Expediente no 2163. Caja 2598. 
de julio de 1958 dos parejas de piedras al molino «La paloma blanca» situado en Alcalá de Guadaíra ${ }^{82}$ (Sevilla) y propiedad de la empresa "Ramón Guillén, S.A.". Las piedras de este molino, de 1 metro de diámetro, equivalían en el sistema de cilindros a una longitud trabajante de 1,56 metros o a $3.120 \mathrm{~kg} /$ día de capacidad molturadora de trigo. Tanto el SNT como la Dirección General de Industria habían autorizado el traslado de dichos derechos industriales desde Alcalá de Guadaíra a Almagro. Su propietario, Vicente Vicente Pérez, tenía instalados en su fábrica de harinas de Almagro solamente 1 metro de los 1,56 adquiridos, por lo que vendió los restantes $560 \mathrm{~mm}$ a Germán García Luengos, con sus derechos industriales inherentes, por 9.000 pesetas, según la escritura de compraventa hecha en Almagro el 10 de marzo de $1959^{83}$.

Tras solicitárselo, el 12 de marzo de 1959 la Delegación de Industria de Ciudad Real autorizó el traslado de los 0,56 m de longitud trabajante hasta Gordoncillo, y la DIL también informó favorablemente el 24 de marzo. El 25 de septiembre la Dirección General de Industria dio un plazo de seis meses para completar el traslado y, finalmente, el 2 de diciembre de ese mismo año Germán García Luengos comunicó que la ampliación ya estaba realizada. Hay que precisar que de dichos 560 mm adquiridos en Almagro sólo se usaron 0,5 metros en Gordoncillo.

Con ello, a finales de 1959 la definitiva capacidad molturadora de la fábrica de harinas «Marina Luz» se estableció en 4`6 metros de longitud trabajante en la línea de molturación, equivalentes a una molienda de 9.200 kilogramos de trigo en 24 horas. Del Acta de comprobación y autorización de puesta en marcha realizada por Antonio Mota López para la DIL el 12 de julio de 1960 extraemos como quedó definitivamente constituida la fábrica de Gordoncillo:

(...) consta de: Una instalación automática para molturación de trigos de la casa Buhler, con transporte mecánico de mercancías compuesta de:

LIMPIA: Un monitor $n^{\circ}$ 53293.- Una deschinadora de seis calles $\sin n^{\circ}$ de fabricación.- Un triarbejón (sic) rápido de $1600 \times 450 \mathrm{~mm}$., sin $n^{\circ}$ de fabricación.- Una despuntadora $n^{\circ}$ 53245.- Un rociador automático $n^{\circ}$ 53198.- Tres depósitos dobles de $1.300 \mathrm{Kg}$. cada sección.- Un aparato

${ }^{82}$ Se conoce popularmente a esta localidad como Alcalá de los Panaderos ya que durante siglos abasteció de pan a Sevilla, para lo cual se instalaron numerosos molinos aprovechando la energía hidráulica del río Guadaíra.

83 AHPL. R.I. 2356. Expediente $n^{\circ}$ 2163. Caja 2598. Copia de la escritura de compraventa, realizada en la notaría de Arsenio Cerro y Sánchez-Herrera. Gumersindo Sáez de Miera, industrial vecino de León, concejal en Valencia de Don Juan en 1955, fue el representante de Germán García en esta compraventa, quizás en compensación por haberle vendido para su fábrica «La Coyantina» parte de los derechos comprados a la harinera de Miranda de Ebro. 
La industria harinera en la provincia de León durante el franquismo: la fábrica de harinas...

magnético.- Una satinadora $n^{\circ}$ 53597.- Un aparato magnético.- Un depósito de espera de molienda.

Aspiración de limpia: Monitor, triarbejón [sic] y despuntadora con aspirador de $500 \mathrm{~mm}$. Ø, $n^{\circ} 562$ y ciclón.- Satinadora con aspirador incorporado y ciclón.

FÁBRICA: Cuatro molinos dobles, tres de ellos $n^{\text {os }} 66710,66711$ y 66712, de 600 × 220 mm. y uno, $n^{\circ}$ 60140, de 500 × 220 mm. dispuestos en el diagrama de fábrica en:

- Cuatro pasadas de trituración, tres de 600 x 220 mm. y una de 500 x $220 \mathrm{~mm}$.

- Cuatro pasadas de compresión, tres de 600 x 220 mm y una de 500 x $220 \mathrm{~mm}$.

Longitud trabajante total: $4.600 \mathrm{~mm}$.

Un desatador-adelantador de molienda $n^{\circ}$ 54632.- Un desatador $n^{\circ}$ 53729.- Un plansichter $n^{\circ}$ 9622, de dos cuerpos, formado cada cuerpo por cuatro calles y ocho tamices de 1.600 × $970 \mathrm{~mm}$. (medida exterior).- Un sasor doble, sin $n^{\circ}$, con ocho tamices de $560 \times 280 \mathrm{~mm}$. (medida exterior).Un torno exagonal (sic), sin $n^{\circ}$, de $3.000 \times 850 \mathrm{~mm}$.- Una cepilladora de salvados modelo MKKa-2.- Una cepilladora para tercerillas modelo MKKa1.- Dos mezcladoras de mercancías $n^{o s} .53289$ y 53290.

Aspiración de fábrica: Un aspirador, marca Rico Cuenca, de $900 \mathrm{~mm}$. Ø, con recolector de polvos de 120 mangas.

CLASIFICACIÓN Y MEJORA DE SUBPRODUCTOS: Un tobogán.- Un torno exagonal (sic) de $3.000 \times 850 \mathrm{~mm}$., como divisor de salvados.

FUERZA MOTRIZ: Un electromotor de 10 C.V., marca Wagner, $n^{o}$ 192529, para limpia.- Un electromotor de 30 C.V., marca ASEA, $n^{\circ} 202366$, para fábrica $^{84}$

En las actas de revisiones de años posteriores no aparecen modificaciones.

\subsection{Crisis y cierre de la fábrica (1961-1965)}

Es a priori sorprendente que apenas cuatro meses después de terminar la ampliación de la fábrica de harinas «Marina Luz» de Gordoncillo, con la que esta alcanzó su mayor capacidad molturadora, nos encontremos a mediados de 1961 con un comunicado de crisis por parte de la Delegación Provincial del Ministerio de Trabajo en el que la sociedad Harino-Panadera de Gordoncillo, S.L. solicitó una reducción de personal ${ }^{85}$. Sin embargo no es un caso aislado, puesto que el sector harinero estaba en aquellos momentos inmerso en una profunda crisis

\footnotetext{
${ }^{84}$ Ibídem, Acta del 12 de julio de 1960.

85 Ibídem, Comunicado de la Delegación Provincial del Ministerio de Trabajo: Crisis no 6/611310, fecha 15 de febrero de 1961.
} 
causada, fundamentalmente, por el exceso de capacidad molturadora existente en toda España, fruto de proliferación de harineras en las últimas décadas. A ello se unía el aumento de las rentas medias de los españoles, en el marco de recuperación económica tras la dura y larga posguerra, lo que implicaba un descenso en el consumo del pan. Si el sector producía ya por encima de la demanda y esta además progresivamente disminuía, era evidente que la crisis estaba servida.

Hasta muchos años después las autoridades competentes no harán prácticamente nada para paliar el hundimiento del sector. Como vimos, las delegaciones de Industria provinciales se limitaban a poner de manifiesto el exceso productivo, pero la Dirección General no prohibía los traslados de derechos entre fábricas con lo que existían empresas, como sucedió en este caso, que ampliaban sus instalaciones a finales de los cincuenta, cuando ya era palpable el negativo devenir del sector.

En el caso de Gordoncillo, la petición de reducción de plantilla se reiteró en 1962 , especificándose que se quería despedir a dos trabajadores ${ }^{86}$. Sea como fuere, el número de trabajadores se mantuvo en dos administrativos y siete obreros hasta el cierre definitivo de la industria.

Por los datos facilitados por el SNT a la DIL, la última molturación de la fábrica de harinas «Marina Luz» tuvo lugar durante la campaña 1964/65. En un nuevo comunicado de crisis de la Delegación Provincial del Ministerio de Trabajo, el 25 de febrero de 1965 se indicaba ya la solicitud definitiva del fin de la actividad de esta industria: Por la empresa Harino-Panadera de Gordoncillo, S.L. (...) fábrica de harina, se solicita de esta Delegación autorización para: cierre y despido del personal $l^{87}$. El 7 de mayo de 1965 se emitió el informe de cese de actividades por parte de la DIL. El 13 de junio causó baja en el Régimen General de la Seguridad Social y el 20 de agosto comunicó su baja a la Recaudación del Impuesto Industrial, dejando de abonar las cuotas de Licencia Fiscal.

El 6 de octubre de 1965 se acordó el traspaso de la fábrica «Marina Luz» a José Quiñones García, por entonces dueño de la harinera «La Industrial Valenciana» creada en 1926 por Anastasio Ortiz García y que en 1959 era la mayor de las fábricas de harinas de Valencia de Don Juan y la tercera de la provincia de León por capacidad de molturación, con $22.000 \mathrm{Kg}$ en 24 horas $^{88}$. Con aquel arriendo

${ }^{86}$ Ibídem, Crisis n ${ }^{\circ}$ 24/62-7505, fecha 12 de julio de 1962.

${ }^{87}$ Ibídem, Crisis no 4/65-1945, fecha 25 de febrero de 1965.

88 FERNÁNDEZ FERNÁNDEZ (2003). o.c., p. 187. Sus instalaciones se ubican en la actual avenida Juan Carlos I (entonces denominada avenida de Roma), pero la fábrica permanece cerrada desde 1989. 
temporal, el coyantino José Quiñones García se convirtió en el mayor empresario harinero de la provincia ${ }^{89}$, superando a Santiago Alfageme y Cía., pero el traspaso de la fábrica de Gordoncillo sólo durará cinco meses, ya que el 8 de marzo de 1966 volvió a manos de Germán García Luengos ${ }^{90}$.

Por tanto, desde comienzos de 1965 podemos considerar a la fábrica de harinas como productivamente cerrada, sin embargo, su actividad administrativa continuará durante unos años más, interviniendo en gestiones muy interesantes que son reflejo de la evolución del sector harinero en un periodo de crisis, con la tardía actuación del Estado en el tardofranquismo, como veremos más adelante. Antes vamos a aportar algunos datos que no han aparecido, al respecto de la vida fabril de esta industria.

\section{DATOS REGISTRALES, PRODUCTIVOS, LABORALES Y COMER- CIALES}

Registro Industrial: La harinera de Gordoncillo estuvo inscrita desde el 20de octubre de 1960 en el Registro Industrial de la provincia de León con el número: 24/02356. Su propietario fue Germán García Luengos y su arrendataria "HarinoPanadera de Gordoncillo, S.L.”. A requerimiento de la Delegación provincial del Ministerio de Trabajo, el 7 de mayo de 1965 el Registro Industrial emitió informe sobre cese de actividades.

Registro en la Seguridad Social: Harino-Panadera de Gordoncillo, S.L. estaba inscrita en el Régimen General de la Seguridad Social teniendo el número: 24/13141. El día 13 de junio de 1965 causó baja por cese de actividad.

Producción (Fuente: AHPL):

Tabla 5. Capacidad de molturación (Trigo)

\begin{tabular}{cccc}
\hline Desde 1936 & Desde 1945 & Desde 1958 & Desde 1959 \\
\hline 2,4 m de long. trab. & $2,90 \mathrm{~m}$ de long. trab. & $4,10 \mathrm{~m}$ de long. trab. & $4,60 \mathrm{~m}$ de long. trab. \\
4.800 Kg trigo al día & $5.800 \mathrm{Kg}$ trigo al día & $8.200 \mathrm{Kg}$ trigo al día & $9.200 \mathrm{Kg}$ trigo al día \\
\hline
\end{tabular}

Tabla 6. Productos obtenidos en 24 horas de molturación a partir de 9.200 kg de trigo

\begin{tabular}{ccc}
\hline Harinas & Salvados & Restos de limpia \\
\hline $6.900 \mathrm{Kg}$ & $2.116 \mathrm{Kg}$ & $184 \mathrm{Kg}$ \\
$75 \%$ & $23 \%$ & $2 \%$ \\
\hline
\end{tabular}

${ }^{89}$ Según datos de licencias fiscales de 1965. ACOCIL.

90 AHPL. R.I. 2356. Expediente n ${ }^{\circ}$ 2163. Caja 2598. 
Tabla 7. Molturación total realizada por campañas

\begin{tabular}{ccccc}
\hline $1960 / 61$ & $1961 / 62$ & $1962 / 63$ & $1963 / 64$ & $1964 / 65$ \\
\hline $12.740,87 \mathrm{Qm}$ & $11.017,94 \mathrm{Qm}$ & $9.818,74 \mathrm{Qm}$ & $8.140,78 \mathrm{Qm}$ & $6.841,35 \mathrm{Qm}$ \\
\hline
\end{tabular}

Tabla 8. Producción anual a obtener (según las revisiones de 1966 y 1967) ${ }^{91}$

\begin{tabular}{lcccc}
\hline & Harinas & Tercerillas & Salvados & Restos limpia \\
\hline Cantidad (Tm) & 436 & 46 & 140 & 13 \\
\cline { 2 - 5 } & $68,65 \%$ & $7,25 \%$ & $22,05 \%$ & $2,05 \%$ \\
\hline \multirow{2}{*}{ Valor (miles Ptas.) } & 3.500 & 240 & 560 & 33 \\
\cline { 2 - 5 } & $80,78 \%$ & $5,54 \%$ & $12,92 \%$ & $0,76 \%$ \\
\hline
\end{tabular}

Empleados: Las informaciones de la DIL indican que entre 1961 y 1965 trabajaban en la fábrica 7 obreros varones mayores de 18 años y dos administrativos. Según el valioso testimonio de Raimundo Tejedor Velado, además de él como segundo molinero, sabemos que otros tres obreros constituían el cuerpo de fábrica: Urbano, Victorino y Ramiro. Como primeros molineros trabajaron en esta fábrica, al menos, Rafael Rey y Félix Álvarez Pascual. Además de ellos, en tareas de empaque ${ }^{92}$ y almacenaje trabajaban otras dos personas, Justino y Feliciano, y ocasionalmente José y Eugenio. Los obreros trabajaban en turnos de 8 horas y mientras quedase cupo la fábrica molturaba las 24 horas. Con ironía nos habla Raimundo Tejedor del mal reparto de los turnos en la fábrica «Marina Luz»: "allí en mi pueblo, como éramos muy valientes, pues hacían esto, la esclavitud, y se empezaba a las ocho de la mañana hasta las cuatro de la tarde, y tenían que ir las pobres mujeres a llevarnos la comida, y por la noche la cena”. Raimundo Tejedor nos facilitó incluso una de sus nóminas, correspondiente a la mensualidad de octubre de 1956, según la cual cobró un total de 1.340,35 pesetas.

Materias primas (Fuente: AHPL)

Tabla 9. Consumos Anuales (1965)

\begin{tabular}{lcc}
\hline & Cantidad & Coste \\
\hline Energía eléctrica & $445.000 \mathrm{kWh}$. & 53.500 pesetas \\
\hline Trigo & $640 \mathrm{Tm}$. & 3.866 .000 pesetas \\
\hline
\end{tabular}

Ventas: La producción de «Marina Luz» tenía un destino diverso, dependiente durante muchos años de la Comisaría General de Abastecimientos. Como HarinoPanadera de Gordoncillo, S.L. también se dedicaba a la producción de pan, una

\footnotetext{
91 Para estos años la industria ya estaba cerrada, aunque los datos nos sirven como indicador.

92 “En Gordoncillo toda la saquería se hacía en yute, con sacos de 100 kilos” testimonio de Raimundo Tejedor.
} 
buena parte de la harina se transformaba en "la tahona" de la propia empresa, donde trabajaban 5 o 6 empleados. Según Raimundo Tejedor Velado, esos panes eran vendidos en Gordoncillo y en varios pueblos limítrofes como Valderas, Fuentes de Carbajal, Valdemora, Carbajal de Fuentes o Castilfalé, donde los repartía el señor Julián Burón que conducía un carro tirado por una caballería. Por otro lado, la harina producida por la fábrica también era vendida a la panadería "Prieto" de León, que la recogía en Gordoncillo en un camión. Por último, no podemos olvidar que la fábrica «Marina Luz» durante el periodo autárquico fue de las denominadas de cupo y canje, por lo que los agricultores de la zona podían acudir a ella a cambiar su cereal por harina.

\section{EL FRANQUISMO ANTE LA CRISIS HARINERA DE LA SEGUNDA MITAD DEL SIGLO XX}

Desde finales de la década de 1950 se puso de manifiesto que, alcanzado el máximo productivo en 1945 bajo el paraguas proteccionista del SNT, se inició un progresivo declive con el cierre de numerosas fábricas de harinas a lo largo de toda la geografía del país.

Por medio de la Orden de 16 de agosto de 1965, de Presidencia del Gobierno, se aprobaron las bases generales de la Acción Concertada Harinera, con el objetivo de reestructurar el sector en los aspectos económico, técnico y promocional, ofreciéndose ayudas crediticias, bonificaciones tributarias y medidas estimuladoras para la exportación ${ }^{93}$. Sin embargo, tales acciones no incidían sobre el verdadero problema del sector y fueron absolutamente insuficientes, como se puso de manifiesto al término de los cuatro años en que tuvieron vigencia. Así, una nueva Orden de 24 de septiembre de 1970 decidió abrir un nuevo plazo de admisión, esta vez aclarando que los conciertos sólo se realizarían con las harineras que presentaran solicitudes de destrucción o desmantelamiento de, al menos, 5.000 metros de longitud trabajante ${ }^{94}$.

El 23 de diciembre de 1970, Germán García Luengos solicitó que su empresa fuera acogida a dichos beneficios. Sin embargo, dado el largo periodo de inactividad de su factoría, la Dirección General de Industrias Textiles, Alimentarias y Diversas, dependiente del Ministerio de Industria, se pronunció de manera

93 BOE $\mathrm{n}^{\circ}$ 202, del 24 de agosto de 1965. Se desarrolló mediante una nueva Orden de 30 de noviembre de 1965 (BOE $\mathrm{n}^{\circ}$ 289).

${ }^{94} \mathrm{BOE} \mathrm{n}^{\circ} 235$, del 1 de octubre de 1970. 
desfavorable ante tal petición, e inició el expediente de caducidad y cancelación, acciones que quedaron declaradas el 7 de septiembre de $1973^{95}$.

El Decreto de 17 de agosto de 1973 aprobó el Plan de Reestructuración del Sector de Harinas, Panificables y Sémolas ${ }^{96}$ en cuyo texto el Gobierno franquista asumía el "exceso de capacidad productiva frente a las necesidades del consumo" y la "ínfima productividad", alegaba "dificultades de índole jurídica y económica" para cumplir la Acción Concertada Harinera y finalmente proponía: “deberán ser ofrecidos al cierre y destruidos hasta un máximo de 4.000 metros de longitud trabajante fabril instalada". Se indicaba además que el metro retirado se pagaría a 100.000 pesetas y que las empresas cerradas no podrían reabrirse hasta pasados, al menos, 30 años.

En último término establecía una segunda disposición transitoria que incluía en el Plan a las empresas acogidas al subsidio de paro establecido en la Orden de 24 de marzo de 1958 que no hubiesen vuelto a reanudar su actividad y que mantuvieran sus instalaciones fabriles, indicando además que la indemnización para ellas sería de 125.000 pesetas por metro de longitud trabajante. Seguramente por ello, y aunque la DIL ordenó el definitivo corte de suministro eléctrico a la fábrica de harinas «Marina Luz» el 24 de septiembre de 1973, Germán García Luengos presentó el 14 de marzo de 1974 un informe para acogerse al Plan de Reestructuración. Pese a todos los recursos, interpuestos ya por su hijo Gabriel García-Luengos -tras la muerte de su padre-, el Ministerio de Industria argumentó defectos de forma e insuficiencia documental, datándose en 9 de noviembre de 1976 el último trámite que conocemos sobre esta harinera.

\section{CONCLUSIONES}

Una pequeña fábrica de harinas como la que hemos elegido nos ha servido para observar las vicisitudes del sector harinero en la provincia de León durante la dictadura franquista, pues justamente la harinera «Marina Luz» inició su producción en 1936, año del golpe militar, dejó de molturar en 1965 y fue clausurada administrativamente entre 1973 y 1976.

Hemos visto su gestación en momentos de incertidumbre, cuando el sector vislumbraba que, tras el aumento productivo generado por la gran demanda

95 AHPL. R.I. 2356. Expediente $n^{\circ}$ 2163. Caja 2598: Ministerio de Industria... SG.322.1702 $\mathrm{GA} / \mathrm{cz}$.

96 Decreto 2244/1973 de Presidencia del Gobierno, publicado en el BOE nº 227, del 21 de septiembre de 1973. 
exterior durante la I Guerra Mundial, la capacidad molturadora española superaba ampliamente las necesidades internas del país. Ello hizo que la burguesía harinera española, en general siempre cercana a los postulados ideológicos más conservadores, buscase una fuerte protección que mitigara su pereza a evolucionar y adaptarse a las nuevas situaciones económico-sociales, por lo que se encontrará especialmente cómoda con los regímenes autoritarios.

Los propietarios agrarios, junto al clero y al ejército, fueron las principales bases de la conspiración antirrepublicana, pero en las mesetas también se sumaron a ellos de manera entusiasta el campesinado medio y las élites rurales, que ya habían dirigido los grupos locales de la Unión Patriótica primorriverista. De los últimos sectores surgieron los nuevos empresarios harineros, con aspiraciones más modestas que los decimonónicos, pero igualmente ávidos de regímenes que protegieran y garantizasen sus negocios.

Para satisfacerles, ya en plena Guerra Civil, en la zona controlada por los sublevados se implantó la regulación de la producción y comercialización del cereal por parte del SNT, de la harina y del pan por parte de la Comisaría General de Abastecimientos. Pero tras el aplauso inicial "las medidas populares pronto se quiebran en desencanto" ${ }^{97}$ pues los beneficios claramente se dirigieron sólo a las élites, no tanto a la capa media campesina que sufrió los perjuicios del descenso productivo, de la caída del consumo por el racionamiento y del recorte de precios y salarios. Serán también las élites locales quienes en buena medida controlen el mercado negro y se repartan los cupos de producción y molturación. Por ello podemos decir que el franquismo recibió el apoyo de la nueva burguesía harinera ${ }^{98}$ y que, implantada la dictadura, esta les correspondió con la esperada protección, necesaria para su artificial pervivencia durante dos décadas.

Así, los años cuarenta significaron la mayor expansión de la industria harinera en nuestro país, impulsada por la legislación del Nuevo Estado y por el reparto de los cupos de cereal que favorecieron la atomización del sector. En 1945 España alcanzó un total 1.878 fábricas de harinas ${ }^{99}$. Su evolución en una economía de libre

97 FERNÁNDEZ FERNÁNDEZ (2003). o.c,. p. 35.

98 Harino-Panadera de Gordoncillo, S.L. aparece como suscriptora del Boletín Sindical “Trabajo" en un listado comarcal publicado por FERNÁNDEZ FERNÁNDEZ (1991). Sindicalismo vertical franquista... pp. 59-62 que, según este mismo autor, refleja personas que desde luego son apologistas del Nuevo Estado y se imbuían de un ardoroso espíritu falangista que convirtieron en pauta moral de vida cívica. Ellos mismos aseguran que nada cambie fuera de su estricto control.

99 Benito ArRanz (1962). "La industria harinera...” p. 181. Cita datos extraídos de la revista Tolva, concretamente del número 31 (diciembre de 1945). 
mercado hubiese significado lo contrario, la concentración en grandes factorías y el aumento de la productividad. Por tanto la protección significaba pan para hoy y hambre para mañana, pues tarde o temprano la burbuja harinera habría de estallar. Lo único positivo que quedará de ello en el futuro será el numeroso patrimonio industrial a preservar.

El descenso del consumo del pan frenó la demanda interna desde finales de los cincuenta, y no existían mercados extranjeros donde colocar los excedentes, por más que la propaganda franquista recurriera a campañas como la "Operación Oriente” por la que se exportó harina a Egipto. Otras tímidas medidas tampoco pudieron frenar la crisis. Nos encontramos ya en un nuevo franquismo, el posterior al Plan de Estabilización (1959) que liquidó la autarquía.

La inevitable consecuencia de todo ello fue el brutal ajuste del sector harinero en los años sesenta y setenta. Así, en el año 1971 las harineras que existían en 1945 quedaron reducidas a la mitad ${ }^{100}$. Al final de la dictadura de Franco su Gobierno quiso reaccionar con el Plan de Reestructuración del Sector de Harinas, Panificables y Sémolas, pero esta medida fue tardía e insuficiente.

\section{BIBLIOGRAFÍA}

Ansola Fernández, A. y Sierra Álvarez, J. (2007). Caminos y fábricas de harina en el corredor del Besaya. Historia, geografía y patrimonio. Santander: Consejería de Medio Ambiente, Gobierno de Cantabria.

Ayuntamiento De GoRDOnCILlo (2003). Gordoncillo. León: Editorial Mic.

BARCIELA LÓPEZ, C. (1981). Tesis doctoral, edición facsímil de la Universidad Complutense de Madrid.

BENITO ARRANZ, J. (1962). "La industria harinera española y su significación en la provincia de Valladolid" en la revista Estudios geográficos, CSIC-Instituto Juan Sebastián el Cano, número 87.

Cámara Oficial De Comercio E Industria De León (1957). Economía leonesa, pequeña historia de su evolución (1907-1957). León: Imprenta Casado.

Carasa Soto, P. (1983). "Los pósitos en España en el siglo XIX", en la revista Investigaciones Históricas, Universidad de Valladolid, Vol. 4, pp. 249-304.

CARRERA De LA RED, M. Á. (1990). Las fábricas de harina en Valladolid. Valladolid: Caja de Ahorros Provincial.

Domínguez De VALDeÓn, T. (1925). El libro de Valderas o guía eclesiástica e histórica de esta ilustre villa y su arciprestazgo (Gordoncillo, Roales y Valdefuentes). León: Imprenta Católica.

100 INE. Anuario 1973, Estadísticas industriales. 
La industria harinera en la provincia de León durante el franquismo: la fábrica de harinas...

FERnÁndez FERnÁndez, P. V. (2003). El franquismo en la provincia de León: sus sindicatos verticales (1938-1977). León: Instituto Leonés de Cultura.

FERNÁNDEZ FERNÁNDEZ, P. V. (1991). Sindicalismo vertical franquista en la comarca de Valencia de Don Juan: notas para su estudio. León: Diputación.

GARCía ABAD, A. (1968). Historia de Valderas y su término. Burgos: Editorial Monte Carmelo.

GARCía De LA Foz, J. (1867). Crónica de la provincia de León. Madrid: Rubio y Cía. Reedición (2002) Valladolid: Editorial Máxtor.

GARCíA FernÁnDEZ, T. (1948). Historia de la villa de Valencia de Don Juan (León) (Antigua Coyanza). Valladolid: Graficas Castilla y Sus-Se.

Helguera, J., García TAPiA, N., Y Molinero, F. (1988). El Canal de Castilla. Valladolid: Consejería de Cultura y Bienestar Social, Junta de Castilla y León.

JiMÉNEZ Y Guited, F. (1862). Guía fabril e industrial de España. Barcelona: Luis Tasso.

Marcos Del Olmo, Ma C. (2002). La Segunda República y la Guerra Civil. Madrid: Actas.

Moreno LÁzARO, J. (1998). La industria harinera en Castilla y León. Tesis doctoral inédita.

Moreno LÁzARo, J. (1990). La industria harinera en Castilla y León (1841-1864), Asociación Empresarial de Fabricantes de Harina de Castilla y León.

OJEDA SAN MigueL, R. (2001). Estudios de historia y arqueología industrial en Miranda de Ebro. Miranda de Ebro (Brugos): Fundación Municipal de Cultura.

Prieto LóPEZ, A. (2007). Historia de la villa de Gordoncillo. 2 tomos. León: Edilesa.

Revilla Casado, J. (2008). La fábrica de harinas «Marina-Luz» de Gordoncillo (León). Historia de una pequeña industria terracampina, Depósito Legal LE-7-2008, trabajo inédito.

RodRíguez GonzÁLEZ, J. (2003). León bajo la dictadura franquista (1936-1951). León: Universidad.

SÁEz, E. (1987). Colección documental del Archivo de la Catedral de León (775-1230). León: Centro de Estudios e Investigación 'San Isidoro'.

Servicio Nacional Del Trigo (1958). Veinte años de Actuación. Madrid: Ministerio de Agricultura.

\section{SIGLAS Y ABREVIATURAS}

\section{Fuentes}

ACOCIL: Archivo de la Cámara Oficial de Comercio e Industria de León

AHPL: Archivo Histórico Provincial de León

AMG: Archivo Municipal de Gordoncillo

BOE: Boletín Oficial del Estado

BOPL: Boletín Oficial de la Provincia de León.

CDMH: Centro Documental de la Memoria Histórica (antiguo Archivo de la Guerra Civil Española)

INE: Instituto Nacional de Estadística

RAE: Real Academia Española de la Lengua 
R.I.: Registro Industrial

\section{Instituciones}

DIL: Delegación de Industria de la provincia de León SNT: Servicio Nacional del Trigo 